\title{
PERAMALAN TRANSAKSI PENJUALAN DENGAN METODE HOLT-WINTER'S EXPONENTIAL SMOOTHING
}

\author{
G. A. N. Pongdatu ${ }^{1}$, Egi Abinowi ${ }^{2}$, Wahyuddin $S^{3}$ \\ Teknik Informatika ${ }^{1}$, Sistem Informasi ${ }^{2}$, Manajemen Informatika ${ }^{3}$ \\ Universitas Kristen Indonesia Toraja ${ }^{1}$, Universitas Widyatama ${ }^{2}$, \\ AMIK Lamappapoleonro Soppeng ${ }^{3}$

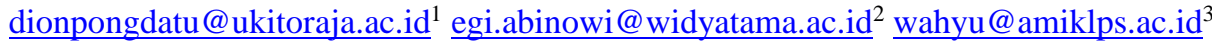

\begin{abstract}
Abstrak
Peramalan merupakan salah satu strategi yang cukup signifikan untuk meningkatkan keuntungan bisnis. Peramalan transaksi penjualan dapat membantu para pengambil keputusan dalam suatu bisnis untuk menentukan strategi penjualan yang akan diterapkan. Peramalan penjualan dilakukan dengan metode Holt Winter's Exponential Smoothing. Model Holt Winter's Exponential Smoothing akurat dalam memperkirakan data deret waktu musiman, baik polanya menunjukkan tren maupun tidak. Kedua model tersebut dibandingkan dengan data perkiraan yang menunjukkan pola musiman. Data yang digunakan adalah data penjualan toko retail pakaian tahun 2014 sampai tahun 2018. Tingkat akurasi model diukur dengan membandingkan persentase nilai peramalan dengan nilai sebenarnya. Nilai ini disebut Mean Absolute Deviation (MAD). Berdasarkan hasil perbandingan, model terbaik dengan nilai MAD terkecil adalah model multiplikatif dengan smoothing weight 0,2 . Kesimpulan ini disimpulkan berdasarkan perbandingan nilai error terkecil dengan nilai MAD 4,38 .
\end{abstract}

Kata kunci :

Peramalan, Penjualan, Holt-Winter's Exponential Smoothing, Deret waktu

\begin{abstract}
Forecasting is a significant strategy to increase business profits. Forecasting sales transactions can help decision makers in a business to determine the sales strategy to be implemented. Sales forecasting is carried out using the Holt Winter's Exponential Smoothing method. Holt Winter's Exponential Smoothing model is accurate in predicting seasonal time series data, whether the pattern shows a trend or
\end{abstract}

not. The two models are compared with forecast data which shows a seasonal pattern. The data used is the sales data of clothing retail stores from 2014 to 2018. The accuracy of the model is measured by comparing the percentage of the forecast value with the actual value. This value is called Mean Absolute Deviation (MAD). Based on the comparison, the best model with the smallest MAD value is the multiplicative model with a smoothing weight of 0.2. This conclusion is concluded based on the comparison of the smallest error value with the MAD value of 4,38.

Keywords :

Forecasting, Sales, Holt-Winter's Exponential Smoothing, Time series

\section{Pendahuluan}

Time-series adalah rangkaian pengamatan terhadap suatu variabel yang diambil dari waktu ke waktu dan dicatat secara berurutan sesuai urutan waktu [1]. Teknik peramalan time series dengan metode kuantitatif dibagi menjadi dua model. Model pertama adalah Model Time-series, yaitu metode peramalan dengan menganalisis variabel yang akan diestimasi dengan variabel waktu. Beberapa metode Model Time Series adalah Weight Moving Average, Arima, SARIMA, Naïve Models, Double Moving Average, Single Exponential Smoothing, Double Exponential Smoothing, dan Holt-Winter's Exponential Smoothing. Kedua, Model Kausal adalah metode peramalan dengan menganalisis pola hubungan antar variabel untuk diestimasi dengan variabel lain yang mempengaruhinya (waktu dan bukan waktu). Metode ini sering disebut dengan metode kausalitas atau eksplanatori, dengan metode seperti Model InputOutput dan Regresi [2]

G. A. N. Pongdatu, Egi Abinowi, Wahyuddin S 
Dalam teknik peramalan Time Series tidak jarang data menunjukkan pola trend, dimana pola datanya menunjukkan kecenderungan naik atau turun. Metode Holt-Winter's Exponential Smoothing merupakan metode peramalan dengan pendekatan eksponensial berdasarkan hasil peramalan pada periode sebelumnya. Metode ini juga menambahkan parameter untuk menangani pola data musiman. Ada dua model utama dalam metode Holt-Winter's Exponential Smoothing, yaitu model perkalian dan model aditif. Penentuan model ini dipilih berdasarkan pola musim [3].

Toko Xyz merupakan toko retail yang menjual pakaian jadi seperti kaos oblong, kaos, celana, dan lainlain. Toko ini telah dibuka sejak tahun 2009 dan mulai mencatat data penjualan secara elektronik sejak tahun 2014. Data transaksi yang disimpan tersebut dapat diproses lebih lanjut untuk peramalan pola transaksi kedepannya. Alasan peramalan transaksi ini adalah agar toko dapat menentukan waktu yang tepat untuk melakukan pembelian persediaan.

Penelitian ini akan membandingkan smoothing wight Holt-Winter's Exponential Smoothing dalam upaya menghasilkan peramalan transaksi pelanggan di Toko Xyz dengan akurasi tinggi.

Tabel 1. Metode Holt Winter's Exponential Smoothing

\begin{tabular}{|c|c|c|c|}
\hline $\begin{array}{c}\text { Baik } \\
\text { pada } \\
\text { pola } \\
\text { data }\end{array}$ & Akurasi & Kelebihan & $\begin{array}{c}\text { Kekuranga } \\
\text { n }\end{array}$ \\
\hline $\begin{array}{l}\text { Musima } \\
\mathrm{n} \text { dan } \\
\text { trend }\end{array}$ & $\begin{array}{l}\text { Periode } \\
\text { menenga } \\
\mathrm{h}\end{array}$ & $\begin{array}{l}\text { Akurat dalam } \\
\text { peramalan } \\
\text { pada data } \\
\text { yang } \\
\text { menunjukkan } \\
\text { pola } \\
\text { musiman dan } \\
\text { trend }\end{array}$ & $\begin{array}{l}\text { Membutuhka } \\
\mathrm{n} \quad \text { data } \\
\text { historis yang } \\
\text { lebih banyak }\end{array}$ \\
\hline
\end{tabular}

\section{KAJIAN LITERATUR}

Dalam bisnis sandang, secara umum diketahui bahwa permintaan konsumen sangat tidak stabil. Pilihan mode konsumen umumnya didasarkan pada harga. Dalam hal ini, untuk mengatasi kondisi tersebut, pengelola toko berusaha menurunkan harga dengan cara menekan biaya produksi atau dengan membeli barang langsung dari pabrik atau pihak pertama.

Metode peramalan deret waktu mungkin merupakan teknik yang paling sering digunakan untuk memprediksi data penjualan. Termasuk dalam teknik statistik ini, berbagai model terkenal yang memiliki dasar statistik formal [4]: perataan eksponensial [5] model Holt-Winters [6] ,model Box \& Jenkins [7], model regresi [8] atau ARIMA. Metode-metode ini telah diterapkan di berbagai bidang dan memberikan hasil yang memuaskan [9]. Untuk meramalkan pola transaksi pelanggan dengan tepat untuk manajemen rantai pasokan, penting untuk memilih model peramalan yang tepat. Pada subbab selanjutnya akan dibahas tentang model peramalan Holt-Winter serta cara mengukur akurasinya.

\section{II.1 Peramalan}

Peramalan adalah kegiatan untuk memperkirakan apa yang akan terjadi pada masa yang akan datang Peramalan merupakan bagian vital bagi setiap organisasi bisnis dan untuk setiap pengambilan keputusan manajemen yang sangat signifikan [10]. Peramalan runtun waktu adalah serangkaian pengamatan terhadap suatu variabel yang diambil dari waktu ke waktu dan dicatat secara berurutan menurut urutan waktu [1].

\section{II.2 Single Exponential Smoothing}

Metode ini juga sering disebut perataan eksponensial tunggal yang biasa dipakai trader untuk peramalan jangka pendek. Model mengansumsikan jika data berfluktuasi di sekitar nilai mean yang tetap, dan juga tanpa trend atau pola pertumbuhan konsisten [11]. Tidak seperti Moving Average, Exponential Smoothing akan menawarkan penekanan yang lebih besar pada runtun waktu melalui penggunaan sebuah konstanta smoothing. Rumus dasarnya adalah:

$$
\mathrm{S}_{\mathrm{t}+1}=\left(a * X_{\mathrm{t}}\right)+(1-\alpha) \mathrm{S}_{\mathrm{t}-1}
$$

$$
\text { dimana: }
$$

a: Konstanta pemulusan

t: $\quad$ Periode waktu

Rumus lain menggunakan ramalan untuk periode sebelumnya dan periode berjalan:

$$
F t=F_{t-1}+a\left(A_{t-1}-F_{t-1}\right)
$$


dimana:

Ft-1 : Perkiraan untuk periode sebelumnya,

At-1 : Permintaan nilai aktual untuk periode tersebut,

a : bobot (harus antara 0 dan 1). Semakin dekat ke nol, semakin kecil bobotnya.

\section{II.3 Double Exponential Smoothing}

Metode ini digunakan saat data menunjukkan trend. Perataan eksponensial dengan tren berlaku seperti single exxponential smoothing kecuali bahwa dua komponen harus diperbarui setiap periode yaitu level dan tren. Levelnya adalah perkiraan yang diratakan dari nilai data pada akhir setiap periode. Tren adalah perkiraan pertumbuhan rata-rata yang diratakan di akhir masing-masing periode [3]. Rumus khusus untuk pemulusan eksponensial sederhana adalah:

$$
\begin{aligned}
& \mathrm{F}_{\mathrm{t}+\mathrm{m}}=\alpha \mathrm{y}_{\mathrm{t}}+(1-\alpha) \mathrm{F}_{\mathrm{t}} \\
& \mathrm{a}_{\mathrm{t}}=2 \mathrm{~S}_{\mathrm{t}}-\mathrm{S}_{\mathrm{t}}{ }^{\prime} \\
& \mathrm{b}_{\mathrm{t}}=\frac{\alpha}{1-\alpha}\left(\mathrm{S}_{\mathrm{t}}-\mathrm{S}_{\mathrm{t}}{ }^{\prime}\right) \\
& \mathrm{S}_{\mathrm{t}}=\alpha \mathrm{y}_{\mathrm{t}}+(1-\alpha) \mathrm{S}_{\mathrm{t}-1} \\
& \mathrm{~S}_{\mathrm{t}}{ }^{\prime}=\alpha \mathrm{S}_{\mathrm{t}}+(1-\alpha) \mathrm{S}_{\mathrm{t}-1}^{\prime}
\end{aligned}
$$

Dimana :

$\mathrm{S}_{\mathrm{t}}$ : adalah nilai perataan exponensial dari $\mathrm{y}_{\mathrm{t}}$ pada waktu $\mathrm{t}$

$\mathrm{S}_{\mathrm{t}}$ : adalah nilai double exponential dari $\mathrm{y}_{\mathrm{t}}$ pada waktu t

$\alpha_{\mathrm{t}} \quad$ : adalah selisih antara nilai perataan eksponensial

$b_{t}$ : adalah faktor penyesuaian

$\mathrm{F}_{\mathrm{t}+\mathrm{m}}$ : adalah peramalan untuk $\mathrm{m}$ periode ke depan.

\section{II.4 Holt-Winter's Exponential Smoothing}

Metode ini digunakan ketika data menunjukkan tren dan perilaku musiman. Untuk mengatasi kemusiman, dikembangkan parameter persamaan yang disebut dengan metode "Holt-Winters" sesuai dengan nama penemunya. Metode Holt-Winters sering disebut dengan pendekatan perataan eksponensial [2]. Metode ini terbagi menjadi dua bagian yaitu metode multiplikatif musiman (multiplicative seasonal method) yang digunakan untuk variasi data musiman yang mengalami kenaikan / penurunan (fluktuasi), dan metode aditif musiman yang digunakan untuk variasi musiman yang konstan.

Model aditif adalah sebagai berikut :

$$
\hat{Y}_{t}=\left(L_{t-1}+T_{t-1}\right) S_{t-p}
$$

Sementara model multiplikatif adalah sebagai berikut:

$$
\hat{Y}_{t}=L_{t-1}+T_{t-1}+S_{t-p}
$$

dimana, konstanta perataan diwakili oleh $\alpha, \gamma$ dan $\delta$. $Y_{t}$ adalah nilai pada waktu $\mathrm{t}$ dan ${ }^{\wedge} \mathrm{Y}_{\mathrm{t}}$ adalah nilai atau ramalan satu periode ke depan, pada waktu t.

\section{II.5 Evaluasi Hasil Peramalan}

Evaluasi hasil peramalan digunakan untuk mengetahui keakuratan hasil peramalan yang telah dilakukan terhadap data yang sebenarnya. Terdapat banyak metode untuk melakukan perhitungan kesalahan peramalan. Beberapa metode yang digunakan adalah : Mean Absolute Deviation adalah ukuran kesalahan peramalan keseluruhan untuk sebuah model. Nilai MAD dihitung dengan mengambil jumlah nilai absolut dari kesalahan peramalan dibagi dengan jumlah periode data (n) [10]

$$
\begin{aligned}
& M A D=\frac{\sum \mid \text { data aktual }- \text { peramalan } \mid}{n} \\
& \text { dimana: } \\
& \mathrm{n}=\text { jumlah periode data }
\end{aligned}
$$

Mean Squared Error merupakan rata-rata selisih kuadrat antara nilai yang diramalkan dan yang diamati. Kekurangan penggunaan MSE adalah bahwa metode evaluasi ini cenderung menonjolkan nilai deviasi yang besar karena adanya pengkuadratan.

$$
M S E=\frac{\sum(\text { kesalahan peramalan })^{2}}{n}
$$

dimana: $n=$ jumlah periode data

Mean Absolute Percentage Error adalah nilai ratarata dari selisih absolut antara nilai hasil peramalan dan nilai aktual, nilai ditunjukkan dalam persentase.

$$
\mathrm{MAPE}=\sum_{t=1}^{T} \frac{\mid \text { peramalan - actual } \mid}{\text { aktual }} * 100
$$




\section{METODE}

\section{III.1 Metode Penelitian}

. Data yang digunakan adalah data penjualan toko retail pakaian tahun 2014 sampai tahun 2018. Tingkat akurasi model diukur dengan membandingkan persentase nilai peramalan dengan nilai sebenarnya.

\section{III.2 Tahap Penelitian}

Tahap penelitian yang akan dilakukan adalah sebagai berikut:

1. Pengumpulan data historis penjualan periode Januari 2014 - Maret 2018.

2. Peramalan inflasi pelanggan dengan menggunakan metode Holt-Winter's Exponential Smoothing

3. Membandingkan hasil peramalan dengan data aktual pada tahun 2018

4. Cek nilai error menggunakan MAD

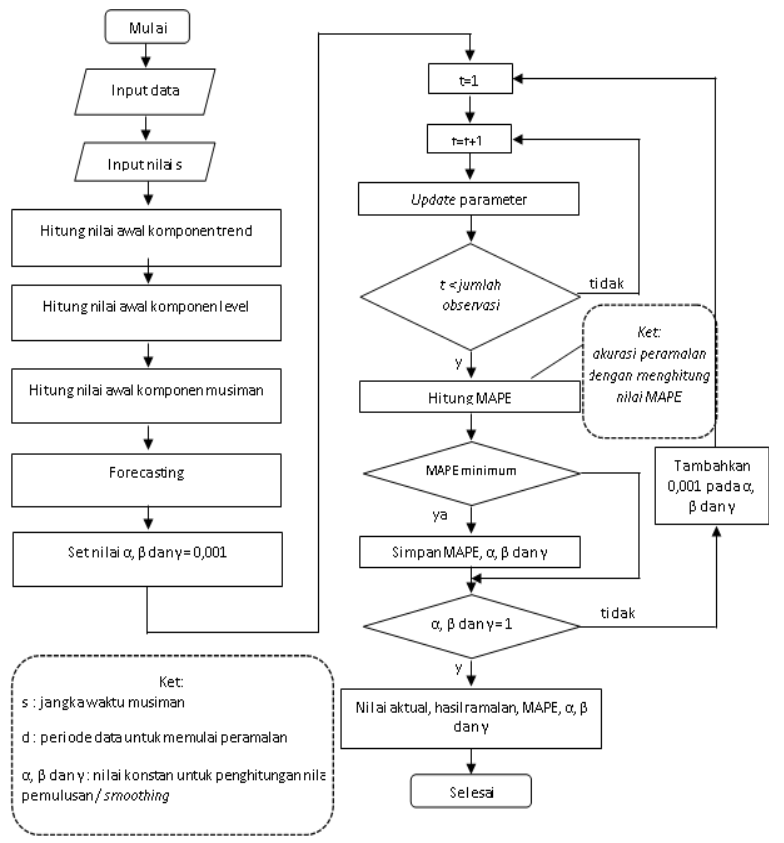

Gambar 1. Tahapan metode Holt-Winter's

Pada gambar 1 ditunjukkan tahapan metode HoltWinters untuk peramalan penjualan dengan data historis selama 3 tahun. Data historis ini dikelompokkan per bulan. Pada metode ini, setelah tahap pengenalan pola data kemudian ditentukan jangka waktu musiman dan periode data untuk memulai peramalan. Kemudian di set nilai awal pembobotan untuk dilakukan peramalan. Dari hasil peramalan ini, dihitung nilai error dengan cara menghitung MAD (Mean Absolute Deviation).

\section{Analisis dan Perancangan}

\section{IV.1 Tahap Penelitian}

Langkah-langkah peramalan dengan metode HoltWinter's Exponential Smoothing adalah menganalisis data apakah mengandung unsur tren dan musiman dengan melihat pola yang terbentuk, kemudian data tersebut diprediksi menggunakan Holt-Winter's Exponential Smoothing dengan metode perkalian musiman atau metode penjumlahan musiman. , kemudian bandingkan dimana nilai kesalahan terkecil diantara kedua metode tersebut. Berdasarkan perbandingan metode perkalian dan penjumlahan ternyata metode perkalian menunjukkan kesalahan yang paling kecil.

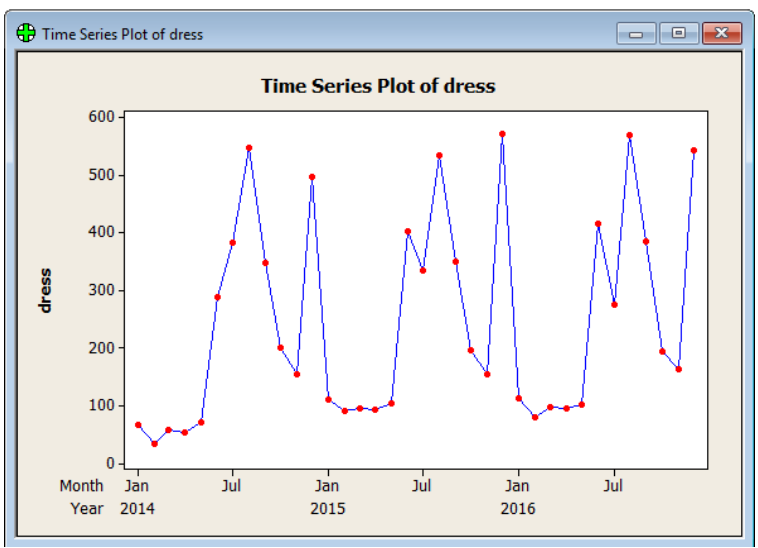

Gambar 2. Plot pola data

Gambar 2 memperlihatkan bahwa data dipengaruhi pola musiman karena terjadi pengulangan pola pada periode tertentu (tahunan).

\section{IV.2 Holt-Winter's dengan model multiplikatif}

Perbandingan hasil peramalan dengan metode Holt-Winter's modelmultiplikatif dapat dilihat pada tabel 3.

Tabel 3. Perbandingan bobot Holt-Winter's model multiplikatif

\begin{tabular}{ccc}
\hline Bobot & MAD & MAPE \\
\hline $\mathbf{0 , 1}$ & 9,51 & 9,80 \\
\hline $\mathbf{0 , 2}$ & 4,38 & 4,71 \\
\hline $\mathbf{0 , 3}$ & 4,82 & 4,91 \\
\hline
\end{tabular}

G. A. N. Pongdatu, Egi Abinowi, Wahyuddin S 


\begin{tabular}{lll}
\hline $\mathbf{0 , 4}$ & 11,36 & 11,36 \\
\hline $\mathbf{0 , 5}$ & 22,46 & 22,31 \\
\hline $\mathbf{0 , 6}$ & 19,70 & 19,42 \\
\hline $\mathbf{0 , 7}$ & 18,28 & 18,04 \\
\hline $\mathbf{0 , 8}$ & 19,67 & 19,46 \\
\hline $\mathbf{0 , 9}$ & 19,71 & 19,37 \\
\hline $\mathbf{1}$ & 19,30 & 18,20
\end{tabular}

Tabel 3 menunjukkan perbandingan hasil peramalan Metode Holt-Winter's Exponential Smoothing dengan model parkalian musiman. Tampak pada tabel 3 bahwa nilai MAD dan MAPE terkecil pada model perkalian musiman adalah hasil peramalan dengan bobot smoothing weight 0,2 dengan MAD 4,38 dan MAPE 4,71.

\section{IV.3 Holt-Winter's dengan model aditif}

Perbandingan hasil peramalan dengan metode Holt-Winter's model aditif dapat dilihat pada tabel 4.

Tabel 4. Perbandingan bobot Holt-Winter's model aditif

\begin{tabular}{ccc}
\hline Bobot & MAD & MSE \\
\hline 0,1 & 19,03 & 20,22 \\
\hline 0,2 & 41,73 & 43,41 \\
\hline 0,3 & 61,65 & 63,88 \\
\hline 0,4 & 49,01 & 50,71 \\
\hline 0,5 & 13,77 & 14,72 \\
\hline 0,6 & 29,65 & 31,73 \\
\hline 0,7 & 69,85 & 73,58 \\
\hline 0,8 & 98,35 & 102,74 \\
\hline 0,9 & 109,64 & 113,67 \\
\hline 1 & 114,99 & 119,44
\end{tabular}

Tabel 4 menunjukkan perbandingan hasil peramalan Metode Holt-Winter's Exponential Smoothing dengan model penambahan musiman. Tampak pada tabel 4 bahwa nilai MAD terkecil pada model aditif adalah hasil peramalan dengan bobot smoothing weight 0,5 dengan MAD 13,77 dan MAPE 14,72 .

\section{IV.4 Hasil Peramalan Dengan Metode Holt- Winter's Exponential Smoothing}

Setelah membandingkan hasil peramalan dengan kedua model Holt-Winter's Exponential Smoothing, maka model dengan nilai error MAD dan MAPE terkecil adalah model perkalian musiman dengan bobot pemulusan 0,2 .

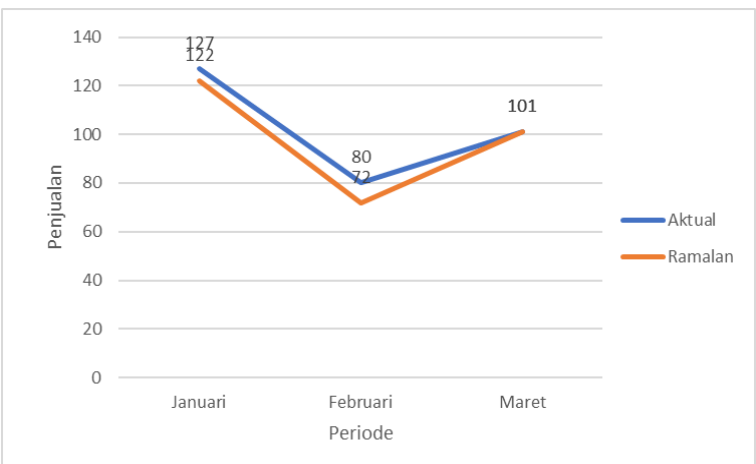

Gambar 3 Grafik perbandingan hasil peramalan

Gambar 3 memperlihatkan grafik perbandingan hasil peramalan dengan data aktual pada periode Januari 2018 - Maret 2018.

\section{KESIMPULAN DAN SARAN}

Peramalan dilakukan dengan metode HoltWinter's Exponential Smoothing dengan menerapkan peramalan transaksi penjualan di toko Xyz. Diketahui bahwa model terbaik untuk meramalkan transaksi penjualan di toko Xyz adalah model multiplikatif dengan smoothing weight 0,2. Kesimpulan ini disimpulkan berdasarkan perbandingan nilai error terkecil dengan nilai MAD 4,38 dan MAPE 4,71.

Dengan hasil peramalan atau perkiraan yang akurat, manajemen toko dapat menentukan strategi yang tepat dalam menentukan waktu dan pemilihan koleksi barang yang akan dipajang atau untuk disimpan terlebih dahulu di gudang.

Untuk penelitian selanjutnya disarankan untuk dapat menghitung hubungan sebab akibat antara transaksi penjualan dengan parameter lain yang berpengaruh terhadap kenaikan atau penurunan jumlah penjualan. 


\section{REFERENSI}

W. W. S. Wei, Time Series Analysis Univariate and Multivariate Methods SECOND EDITION. 2006.

S. G. Makridakis, S. C. Wheelwright, and R. J. Hyndman, "Forecasting: Methods and Applications," J. Forecast., p. 1, 1998.

P. Kalekar, "Time series forecasting using HoltWinters exponential smoothing," Kanwal Rekhi Sch. Inf. Technol., no. 04329008, pp. 113, 2004.

C. W. Chu and G. P. Zhang, "A comparative study of linear and nonlinear models for aggregate retail sales forecasting," Int. J. Prod. Econ., vol. 86, no. 3, pp. 217-231, 2003.

R. G. Brown, "Smoothing, forecasting and prediction of discrete time series Prentice Hall," EngleWood Cliffs, New Jersey, 1959.

H. Vaagen and S. W. Wallace, "Product variety arising from hedging in the fashion supply chains," Int. J. Prod. Econ., vol. 114, no. 2, pp. 431455, 2008.

G. E. P. Box, G. M. Jenkins, and G. C. Reinsel, "Time Series Analysis - Forecasting and Control," Prentice Hall New Jersey 1994, vol. SFB 373, no. Chapter 5, pp. 837-900, 1994.

H. Nair, J.-P. Dubé, and P. Chintagunta, “Accounting for Primary and Secondary Demand Effects with Aggregate Data," Mark. Sci., vol. 24, no. 3, pp. 444-460, 2005.

R. J. Kuo and K. C. Xue, "Fuzzy neural networks with application to sales forecasting," Fuzzy Sets Syst., vol. 108, no. 2, pp. 123-143, 1999.

R. Fahrudin and I. D. Sumitra, "PERAMALAN INFLASI MENGGUNAKAN METODE SARIMA DAN SINGLE EXPONENTIAL SMOOTHING (STUDI KASUS: KOTA BANDUNG)," 2020.

R. Biri, Y. A. R. Langi, and M. S. Paendong, "Penggunaan Metode Smoothing Eksponensial dalam Meramal Pergerakan Inflasi Kota Palu," J. Ilm. Sains, vol. 13, no. 1, pp. 68-73, 2013. 